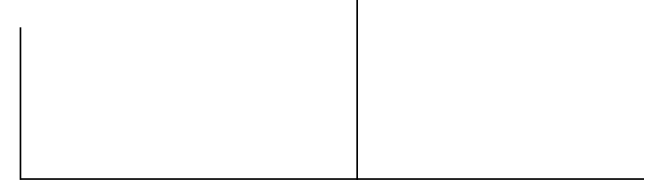

Rev. Latinoam. Psicop. Fund. V, 3, 144-153

\title{
A historiografia sobre o movimento psicanalítico no Brasil
}

\section{Carmen Lucia Montechi Valladares de O liveira}

Ao propormos a publicação do Relatório da Secção de Psicanálise, apresentado durante o III Congresso Brasileiro de Neurologia, Psiquiatria e Medicina Legal de 1929 e intitulado "Contribuição Brasileira à Psicanálise", nosso objetivo é prestar homenagem ao iniciador da historiografia da psicanálise no Brasil, Júlio Pires PortoCarrero.

Além de um ilustre psiquiatra, Porto-Carrero foi igualmente um "fanático da psicanálise” como ele mesmo se nomeava e um dos principais difusores da doutrina entre 1920 e 1938, ano de sua morte. Infatigável, durante esse período ele difunde a psicanálise no meio psiquiátrico local e nacional e sobretudo no meio pedagógico, não sem enfrentar dificuldades e amargar algumas derrotas (Oliveira, 2002).

Durante os anos 1930, ele participa ativamente da equipe de tradutores que publica 7 volumes contendo 52 títulos (conferências, ensaios, artigos e livros) das obras de Freud, pela editora Guanabara, Waissman-Koogan, do Rio de Janeiro. Uma parte dessas traduções será retomada na ocasião da publicação das Obras Completas de Freud, pela editora carioca Delta, em 1958. 
Como diversos médicos brasileiros, Porto-Carrero também se correspondeu com o "mestre de Viena" e chegou mesmo a ser mencionado na biografia de Jones sobre Freud. (Jones, [1955]1990, p. 146). No entanto, contrariamente à afirmação deste autor, não foi Porto-Carrero quem visitou Freud em 1926, mas Henrique Belford Roxo que por sinal, em seu Manual de Psychiatria, publicado em 1921, dedicou um capítulo ao fundador da psicanálise (Jones, 1990, p. 146). Aliás, o próprio Roxo menciona essa visita no necrológio de Freud que assina para os Arquivos Brasileiros de Higiene Mental (Roxo, 1939-1940, p. 101).

Antes de escrever esse Relatório, em 1929, Porto-Carrero já havia abordado a história da psicanálise em outra ocasião, em sua "Aula Inaugural do Curso de Psicanálise Applicada à Educação” de 20 de abril de 1928 e intitulada "Psychanalyse - a sua história e o seu conceito". ${ }^{1}$ Inspirado no texto, "Sobre a história do movimento psicanalítico" (Freud, 1914), ele descreve a passagem de Freud com Charcot, as querelas com Breuer sobre a etiologia sexual das neuroses, a teoria do trauma, a criação da Sociedade Psicológica das Quartas-feiras, as dissidências com Adler, Stekel, Jung e mais tarde Rank, as contribuições de Abraham, Ferenczi, a entrada em cena de Anna Freud, além de passar em revista os principais escritos de seu mestre, para concluir com algumas referências ao movimento psicanalítico brasileiro. Nesse texto, como em diversos outros que escreve, é interessante destacar o quanto Porto-Carrero é atualizado com as obras freudianas assim como a tradução que faz desse método que, segundo ele, "se desenvolveu como systema philosophico e invadiu a esphera inteira das sciencias do espirito" (Porto-Carrero, 1928, p. 14). Um exemplo entre tantos é o rápido comentário que faz de "O futuro de uma ilusão" (1927) nessa Aula Inaugural de 20 de abril de 1928. Para ele, este "hymno ao futuro" ou "utopia psychanalytica" é um "estudo de sociologia e moral, prevê a morte do tabu para melhor felicidade do genero humano" (Porto-Carrero, 1928, p. 21).

Já o Relatório de 1929, escrito em estilo positivista, típico da época, registra exclusivamente os acontecimentos que marcaram os primeiros 15 anos de difusão das teses freudianas no Brasil. Através dele ficamos sabendo que elas circularam por alguns dos principais centros urbanos do país: Rio de Janeiro, São Paulo, Salvador, Porto Alegre, com ecos dela chegando a Vitória no Espírito Santo.

Muitos dos acontecimentos ali assinalados estão hoje em dia corrigidos, outros são contestados, ao passo que outros ainda se perderam, ou ficaram esquecidos. Seria interessante, por exemplo, investigar os efeitos da experiência de Deodato de Moraes como Instrutor Publico de Vitoria em 1929 assim como

1. A aula foi publicada na coletânea de textos intitulada, Ensaios de Psychanalyse (1929, p. 11-25). 
a do seu ensino na cátedra de Psicologia, ambas mencionadas nesse Relatório. ${ }^{2}$ Na realidade, as informações contidas fazem dele um documento histórico fundamental. Texto fundador, é nele que os historiadores da psicanálise se pautam para escrever a história da implantação deste saber no país.

Por outro lado, quando Porto-Carrero apresenta esse Relatório, ele parece otimista para com o futuro do movimento psicanalítico. A história vai mostrar no entanto que serão necessários ainda quarenta anos para que a psicanálise, controlada pela International Psychoanalytical Association (IPA), consiga implantar o conjunto dos seus dispositivos de formação e prática no país, e assim mesmo em apenas três dos principais centros urbanos do país: São Paulo, Rio de Janeiro e Porto Alegre. Um processo que podemos dividir em três etapas marcadas por rupturas e modificações tanto na forma de concebê-la quando de praticá-la. Temos assim:

- 1915-1937, a época da recepção e difusão das idéias psicanalíticas.

- 1938-1950, o momento da formação das primeiras gerações de analistas.

- 1951-1969, a fase da institucionalização do movimento nos moldes da IPA com a criação dos organismos de formação e prática em São Paulo, Rio de Janeiro e Porto Alegre.

A expansão para outras regiões do país vai ocorrer nos anos 1970, agora contando com o nascimento de outras escolas e tendências e a emergência das diferentes psicoterapias que no seu conjunto constituem a chamada clínica "psi”.

Sobre este período, a historiografia brasileira conta em particular com os trabalhos de Cecília Coimbra (1995) sobre as práticas psi nos anos 1970 e 1980 em São Paulo e no Rio de Janeiro baseados em pressupostos deleuzianos. Antes, Jane Russo (1993), fazendo uma leitura antropológica, já havia publicado sua tese de doutoramento sobre a emergência das terapias corporais no Rio de Janeiro. A esses dois trabalhos deve-se acrescentar ainda o documentário produzido pelo Núcleo de Psicanálise, cinema e vídeo. Intitulado Nós outros e a psicanálise, ele reúne depoimentos de 13 personalidades, em grande parte de argentinos que chegam ao Brasil em meados dos anos 1970 e que relatam suas experiências fora da instituição ipeista.

Já no que se refere ao trabalho historiográfico referente ao período de implantação da psicanálise, após a publicação do Relatório de Porto-Carrero, o

2. Membro do Conselho Diretor da Associação Brasileira de Educação e Inspetor Escolar da capital em 1928, além de ex-professor de pedagogia e psicologia experimental na Escola Normal de São Paulo, Deodato de Moraes é igualmente autor de A psychanalyse na educação, o primeiro livro sobre a temática da psicanálise aplicada à educação escrito por um autor brasileiro e publicado provavelmente em 1928. 
próximo registro data de 1948 e foi deixado por Virgínia Bicudo. Fundadora do movimento psicanalítico paulista, neste estudo ela faz uma apologia do movimento lançado por Durval Marcondes em São Paulo. De fato, nesta época ela tem boas razões para homenagear esse fundador. A psicanálise paulista, presente em diversos espaços institucionais, comemora 10 anos de experiência em psicoterapia com crianças e o grupo formado pela analista didata Adelheid Koch já conta sete membros e goza do estatuto de Sociedade provisória afiliada à IPA. Além disso, a disciplina é ensinada na Escola de Sociologia e Política de São Paulo, e no Juqueri, alguns psiquiatras não hesitam em aplicar algumas técnicas de escuta analítica em pacientes hospitalizados.

Após a publicação desses dois textos, de Porto-Carrero e de Virgínia Bicudo, os próximos trabalhos historiográficos só vão reaparecer a partir de meados do anos 1960. Elaborados pelos pioneiros do movimento ou discípulos, temos alguns pequenos textos a caráter regional, como por exemplo o de Luiz Galvão (1967).

Em geral esses escritos são patrocinados por organismos oficiais afiliados à IPA e publicados na Revista Brasileira de Psicanálise (RBP). Neles, com freqüência, a análise é descritiva e reduzida a uma tradição oral, relato de fatos deslocados de seu contexto sócio-cultural, acrescidos de rumores e lendas. Uma pesquisa em fontes primárias foi, no entanto, efetuada por Raymundo Barcellos em 1976, que a pedido do então presidente da Sociedade Brasileira de São Paulo (SBPSP), Laertes Ferrão, passou em revista seis dos livros de atas desta Sociedade (Barcellos, 1976).

Mas é no final dos anos 1970 que a historiografia paulista começa a ganhar forma por intermédio de Roberto Sagawa que toma a iniciativa de gravar e publicar algumas entrevistas com Durval Marcondes feitas em 1979 e 1980, antes de se lançar em sua pesquisa para dissertação de mestrado pela Unicamp, defendida em 1989 e seguida de diversos outros trabalhos (Sagawa, 1989).

Do conjunto dessas publicações se forjou uma história oficial onde, tomando o caso paulista como exemplo, temos um personagem, Durval Marcondes, que aparece como um herói solitário, um Dom Quixote que contra ventos e moinhos funda esse saber num universo psiquiátrico hostil e marginalizado pela intelligentsia médica.

No entanto, nossas recentes pesquisas sobre a implantação da psicanálise em São Paulo nos revelaram um Marcondes bem integrado e participante ativo no meio médico paulista, em particular na Associação Paulista de Medicina (APM). Pudemos constatar também que as resistências à psicanálise, tão alardeadas pela versão oficial, não foram nem maiores nem piores que em qualquer outro lugar. Igualmente, pudemos verificar que muitas das dificuldades 
encontradas na implantação desse saber são menos ligadas às pressões externas que às próprias exigências da IPA de afiliação, que aliás o grupo obtém a duras penas em 1951 (Oliveira, 2001).

A história oficial, acrescida do legitimismo freudiano criado por Jones, ou seja, da produção de uma história pragmática, racionalista e positivista, ganha novo impulso nos anos 1990, quando é criado o Projeto Memória, por iniciativa da direção da SBPSP. Desta pesquisa, que registra os testemunhos de personalidades pioneiras desse movimento, ao mesmo tempo que procura inscrever o movimento psicanalítico no quadro da história social paulista, temos a publicação Álbum de família (Nosek, 1994).

É interessante notar que essa pesquisa, ao procurar recuperar a memória institucional da IPA paulista; ainda que produzindo uma história oficial, estimula a produção de outros escritos sobre esse movimento. Temos então, em estilo biografia, o livro sobre Isaías Melsohn (Sister e Taffarel, 1996) que, de uma certa forma, "corrige” dados dessa história oficial, seguido da coletânea de textos e seminários de Frank Philips gravados e organizados em livro por discípulos (Philips, 1997).

Todos esses textos são posteriores ao estudo de Elisabete Mokrejs sobre as origens do pensamento psicanalítico no Brasil, datando de 1993. Sem questionar a historiografia oficial, a autora apresenta, porém, alguns perfis de "precursores" desse movimento, e um primeiro levantamento das publicações freudianas traduzidas no Brasil e de autores brasileiros sobre a psicanálise (Mokrejs, 1993).

Já no Rio de Janeiro, a historiografia oficial fica a cargo da fundadora do movimento psicanalítico carioca, Marialzira Perestrello, sobretudo em seus trabalhos efetuados nos anos 80 a partir da coleta de depoimentos e documentos reunidos sobre os precursores e as origens desse movimento no país (Perestrello, 1985, 1987, 1991).

Mas, como sempre acontece, foram os limites da história oficial, assim como o próprio contexto de dissidências do movimento psicanalítico carioca, que contribuíram para a elaboração de outros trabalhos historiográficos. São escritos que comportam uma visão crítica e denunciam o silêncio das instituições a propósito dos "buracos negros” dessa história. Entre eles, vale lembrar o livro de Helena Besserman Vianna (1994), ou ainda os de Chaim Samuel Katz, particularmente aquele sobre a ética da psicanálise (Katz, 1984). Ele é publicado, após a expulsão de dois analistas cariocas da Sociedade psicanalítica do Rio de Janeiro (SPRJ), Hélio Pellegrino e Eduardo Mascarenhas, no momento em que vem à tona o caso que diz respeito às ligações de um analista afiliado à IPA com 
torturas praticadas pelos militares durante a ditadura, e conhecido como "o caso Amilcar Lobo". ${ }^{3}$

Já no que se refere à concepção metodológica que inspira os trabalhos historiográficos sobre o movimento psicanalítico no Brasil, pode-se dizer que a ruptura com a história oficial vai aparecer de fato pela primeira vez na dissertação de mestrado em filosofia de Gilberto Rocha, pela PUC-RJ, em 1983 e publicada em 1989. Inspirado no modelo foucaultiano, que vincula o nascimento da psicanálise ao saber psiquiátrico moderno, seu livro reconstitui, a partir da exploração de fontes primárias e secundárias, além de testemunhos, as condições que permitiram a implantação da psicanálise no Brasil (Rocha, 1989), inaugurando assim uma abordagem do movimento psicanalítico que Roudinesco chama de história savante (Roudinesco, 1994).

Mas é finalmente nesses últimos anos que se constata uma verdadeira preocupação para com a produção historiográfica da psicanálise no país. Isso vem se verificando sobretudo no meio universitário, por intermédio de pesquisadores não necessariamente afiliados a grupos ou instituições psicanalíticas. Entre eles, temos a dissertação de mestrado de Jorge Abrão (1999/2001) pela Unesp de Assis e três teses de doutoramento dedicadas ao movimento psicanalítico no Rio de Janeiro, Porto Alegre e São Paulo e pela Universidade Paris VII - DenisDiderot: Fernandes-Boddin (1998), Gageiro (2001) e Oliveira (2001).

3. Analista da Sociedade Brasileira de Psicanálise do Rio de Janeiro (SBPRJ), Helena Besserman Vianna restitui no seu livro o caso que começa em 1973, durante o período mais repressivo da ditadura militar brasileira. Nessa data, ela envia à Sociedade Psicanalítica Argentina uma denúncia publicada no jornal clandestino Voz operária, orgão do Partido Comunista Brasileiro, sobre as ligações com a tortura do psicanalista Amilcar Lobo, em formação na Sociedade Psicanalítica do Rio de Janeiro (SPRJ). A informação é publicada na revista argentina de psicanálise Questionamos e graças a pressões de diversas instituições consultadas, chega à direção da IPA, então dirigida pelo francês Serge Lebovici. Este, após ter consultado os dirigentes envolvidos, conclui que Amilcar Lobo foi caluniado. A partir daí, Besserman Vianna é designada “caluniadora” pelas duas Sociedades cariocas, submetida a intimidações e, pior ainda, passa a ser perseguida pelos militares. No Brasil, o caso se torna público somente em 1980, quando os prisioneiros políticos, torturados pelo regime, denunciam as atrocidades da ditadura e designam Amilcar Lobo como torturador. Por questionarem suas instituições, Hélio Pellegrino e Eduardo Mascarenhas são expulsos. Apesar da repercussão nacional e internacional, principalmente na França e por iniciativa de René Major e Elisabeth Roudinesco, que obrigou a retirada do torturador da lista de afiliados da IPA e ao mesmo tempo questionou a atitude de alguns dos dirigentes das instituições envolvidas, o caso, que sofreu inúmeras reviravoltas, permanece ainda hoje sem uma reflexão de fundo sobre a ética no seio do movimento psicanalítico, e o mal-estar reina entre os psicanalistas. Ver Vianna (1994), Katz (1984) e Fernandes-Boddin (1998). 
Apesar desse renouveau historiográfico, desse esforço de recuperação da memória dos clínicos brasileiros, muito ainda resta a ser produzido. Inúmeras fontes precisam ser localizadas e confrontadas a depoimentos e textos que se encontram dispersos em diferentes publicações e arquivos privados e institucionais. Igualmente, muito pouco se conhece sobre a implantação da psicanálise em outras regiões fora do eixo São Paulo - Rio de Janeiro - Porto Alegre. No seu conjunto, os trabalhos existentes se ressentem particularmente da ausência de arquivos como depositários dessa memória, de fontes primárias para a pesquisa. Ademais, são raras as instituições psicanalíticas que abrem seus arquivos à consulta. Na realidade, não existe da parte delas uma política de arquivos, o que faz com que uma grande parte do material produzido e conservado pelos fundadores desse movimento acabe dispersado, ou então destruído, pelos herdeiros, quando não pela própria instituição.

Ora, todo historiador sabe que tanto a ausência da memória institucional quanto a política de censura dos arquivos, tal qual a adotada pelo Sigmund Freud Archives (SFA), ${ }^{4}$ têm conseqüências trágicas. Além de alimentar e fazer proliferar rumores inúteis, lembra Peter Gay ([1988]1991), os herdeiros do legitimismo, ao suprimir inutilmente vestígios dessa história, acabam por favorecer interpretações fantasmáticas. ${ }^{5}$

Muitas vezes o historiador se depara ainda com a resistência dos psicanalistas em abrir seus arquivos. A resistência dos psicanalistas à história, lembra Roudinesco, mais forte do que em qualquer outra comunidade, é o resultado da maneira como eles mesmos concebem a história, que por outro lado tem a ver também com o próprio conceito psicanalítico de resistência. Assim, salienta a autora:

A resistência à história é o próprio sintoma da resistência interior da psicanálise a ela mesma, ao seu interior, dessa resistência inconsciente dos

4. Os Arquivos Freud, depositados no Departamento de manuscritos da Biblioteca do Congresso em Washington, reúne numerosos documentos, correspondências, manuscritos e entrevistas com personalidades que marcaram a saga freudiana. Eles foram concebidos por Siegfried Bernfeld, imigrante vienense e membro do primeiro círculo psicanalítico, mas, durante muitos anos, foram dirigidos por Kurt Eissler que, apoiado por Anna Freud, estabeleceu um regulamento draconiano de funcionamento com inúmeras restrições à consulta, aliás disponível apenas aos afiliados à IPA. A coleção foi organizada e dividida em séries (A, B, E, F e Z). Atualmente, apenas a série $\mathrm{Z}$ é vetada aos pesquisadores. A suspensão progressiva desse veto está prevista para 2100 (a esse propósito ver Roudinesco, 2001).

5. Tal é o caso da historiografia revisionista de Freud, de Roazen (1971/1973), Masson (1984), Malcolm (1984/1986), e Crews (1995/1999), para citar apenas alguns autores dessa corrente. 
psicanalistas à verdade que eles transformam em hagiografia, em culto do herói sem medo e sem recriminação, em jargão. Essa resistência tem origem em parte do fato que os psicanalistas têm a impressão que o único lugar de enunciação possível da história é o tratamento, o tratamento protegido pelo segredo. De onde a idéia de que a história da psicanálise não pode ser contada porque ela revelaria um segredo: um segredo de divã, um segredo médico. (Roudinesco, 1997, p. 23)

E, no entanto, pode-se dizer que a pesquisa historiográfica encontra um ponto de similitude com a psicanálise na medida em que tanto historiador quanto psicanalista têm em comum a relação com a memória, mesmo se para um a aproximação é pelo individual, enquanto para o outro o enraizamento é no coletivo. No trabalho do historiador, lembra Paul Ricoeur, a equação individual/coletivo pode ser resolvida pela convicção da presença permanente no espírito de algo do passado e pela procura de uma inscrição plural da lembrança (Ricoeur, 2000). O trabalho do historiador, como o do psicanalista, se situa entre a rememoração e o esquecimento, e coloca em causa a questão da representação mnemônica.

Por outro lado, a história é feita de esquecimentos e redescobertas, o julgamento da posteridade também pode ser marcado pelo esquecimento cego. Como lembra Swain, fazer história não é apenas exercer uma desconfiança sistemática ao encontro dos testemunhos do passado e, particularmente, das opiniões de uma época sobre ela mesma, às vezes é também chegar a lhe dar razão, a lhe restituir uma significação que havia perdido (Swain, 1997, p. 79).

Ora, com a publicação desse Relatório de Porto-Carrero, pretendemos contribuir para a restituição da memória de quase noventa anos dessa prática no país, apesar de tão pouco conhecida, e igualmente prestar homenagem à nova geração de clínicos brasileiros.

\section{Referências}

ABRão, Jorge Luís Ferreira. A história da psicanálise de crianças no Brasil. São Paulo: Escuta, 2001.

Barcellos, Raymundo. Algumas anotações biográficas da Sociedade Brasileira de Psicanálise de São Paulo, SBPSP. São Paulo: SBPSP (documento interno), 1994.

Bicudo, Virgínia Leone. Contribuição para a história do desenvolvimento da psicanálise em São Paulo. Arquivos de neuropsiquiatria. São Paulo, v. VI, n. 1, p. 69-72, 1948. Campos, Regina Helena de Freitas (org). Dicionário biográfico da Psicologia no Brasil - pioneiros. Rio de Janeiro: Imago; Distrito Federal: CFP, 2001.

Coimbra, Cecília Maria Bouças. Guardiães da ordem: uma viagem pelas práticas psi no Brasil do "milagre”. Rio de Janeiro: Oficina do ator, 1995. 
Crews, Frederick (1995). As guerras da memória. São Paulo: Paz e Terra, 1999.

FERnandes-Boddin, Cláudia. L'arrivée du freudisme au Brésil et l'implantation du mouvement lacanien à Rio de Janeiro. 1998. Tese (doutoramento em Sociétés occidentales - temps, espace \& civilisation), Université Paris VII - Denis Diderot. Gageiro, Ana Maria. L'histoire de la psychanalyse au Brésil et de la fondation de la Société Psychanalytique de Porto Alegre (1963). 2001. Tese (doutoramento em Sociétés occidentales - temps, espace \& civilisation), Université Paris VII - Denis Diderot.

Galvão, Luiz Almeida Prado. Notas para a história da psicanálise em São Paulo. Revista Brasileira de Psicanálise. São Paulo, v. 1, n. 1, p. 46-68, 1967.

GaY, Peter (1988). Freud une vie. Paris: Hachette, 1991.

Jones, Ernest (1955). La vie et l'œuvre de Sigmund Freud. 3. Les dernières années 1919-1939. 3. ed. Paris: PUF, 1990.

KaTz, Samuel Chaim. Ética e psicanálise. Rio de Janeiro: Graal, 1984.

Malcolm, Janet (1984). Tempête aux archives Freud. Paris: PUF, 1986.

Masson, Jeffrey Moussaïeff. Le réel escamoté. Paris: Aubier, 1984.

Mokrejs, Elisabete. A psicanálise no Brasil. As origens do pensamento psicanalítico. Petrópolis: Vozes, 1993.

Moraes, Deodato de. A psychanalyse na Educação. Rio de Janeiro: Mendonça, Machado \&C., 1928.

Nosek, Leopold (dir.). Álbum de família: imagens, fontes e idéias da psicanálise em São Paulo. São Paulo: Casa do Psicólogo, 1994.

Oliveira, Carmen Lucia Montechi Valladares de. L'implantation du mouvement psychanalytique à São Paulo. 2001. Tese (doutoramento em Sociétés occidentales - temps, espace \& civilisation), Université Paris VII - Denis Diderot.

Os primeiros tempos da psicanálise no Brasil e as teses pansexualistas na educação. Ágora - Estudos em Teoria Psicanalítica, Rio de Janeiro, v. 5, n. 1, jan-jun. 2002.

Perestrello, Marialzira. Primeiros encontros com a psicanálise no Brasil (1899-1937) - Os precursores do Movimento psicanalítico [trabalho apresentado no I Simpósio do Departamento de Pesquisa da SBPRJ, em novembro de 1985]. In: Encontros: psicanálise. Rio de Janeiro: Imago, 1992, p. 111-52.

História da psicanálise no Brasil. O ensino nos Institutos [Relatório apresentado ao Special Discussion Group sobre a História da psicanálise na América Latina, $37^{\circ}$ Congresso da Associação Psicanalítica Internacional, Buenos Aires, 1991], p. $155-82$.

História da Sociedade Brasileira de Psicanálise do Rio de Janeiro: suas origens e fundação. Rio de Janeiro: Imago, 1987.

Philips, Frank. Psicanálise do desconhecido. São Paulo: Editora 34, 1997.

Porto-Carrero, Júlio Pires (1928). Psychanalyse - a sua história e o seu conceito. Ensaios de Psychanalyse. Rio de Janeiro: Flores \& Mano, 1929, p. 11-25. 
Ricoeur, Paul. La mémoire, l'histoire, l'oubli. Paris: Seuil, 2000.

Roazen, Paul (1971). Freud e seus discípulos. São Paulo: Cultrix, 1978.

(1971). Irmão animal, a história de Freud \& Tausk. São Paulo: Brasiliense, 1973.

Rocha, Gilberto S. Introdução ao nascimento da psicanálise no Brasil. Rio de Janeiro: Forense Universitária, 1989.

Roudinesco, elisabeth. L'analyse, l'archive. Paris: Bibliothèque Nationale de France, 2001.

Généalogies. Paris: Fayard, 1994.

Psychanalyse et histoire: résistance et mélancolie. In: Gauthier, R. M.

(org.). Les voies de la psychanalyse. Paris: L’Harmattan, 1997, p. 21-34.

Roxo, Henrique. Manual de psychiatria. Rio de Janeiro: Francisco Alves, 1921. Freud [Noticiários]. Arquivos Brasileiros de Higiene Mental, Rio de Janeiro, v. XII, n. 3-4, jul., p. 101-102, 1939-1940.

Russo, Jane. O corpo contra a palavra: as terapias corporais no campo psicológico dos anos 80. Rio de Janeiro: Editora UFRJ, 1993.

Sagawa, Roberto Y. Durval Marcondes e o movimento psicanalítico. In:

Redescobrir as psicanálises. São Paulo: Lemos Editorial, 1992, p. 82-93.

Durval Marcondes e o início da clínica psicanalítica brasileira. In: Redescobrir as psicanálises. Op. cit., p. 94-99.

Os inconscientes do divã da história. 1989. Dissertação (Mestrado em Psicologia), Universidade de Campinas, 2 vol. 1996.

A construção local da psicanálise. Marília: Editora Interior/Psicanálise,

Sister, Bela e TAFFarel, Marilsa. Isaías Melsohn, a psicanálise e a vida: setenta anos de histórias paulistanas e a formação de um pensamento renovador na psicanálise. São Paulo: Escuta, 1996.

SwaIn, Gladys. Le sujet de la folie. Paris: Calmann-Lévy, 1997.

Vianna, Helena Besserman. Não conte a ninguém... Contribuição à história das Sociedades psicanalíticas do Rio de Janeiro. Rio de Janeiro: Imago, 1994. 